Abstracta Iranicacta Iranica

Revue bibliographique pour le domaine irano-aryen

Volume 22 | 2001

Comptes rendus des publications de 1999

\title{
« Bāz-Hูāānīe dāstān-e Dāš Ākol ». Kārnāme, nº 7, (1378), pp. 63-77. [Relecture du récit de Dāš Ākol]
}

\section{Christophe Balaÿ}

\section{(2) OpenEdition}

\section{Journals}

\section{Édition électronique}

URL : http://journals.openedition.org/abstractairanica/37129

DOI : 10.4000/abstractairanica.37129

ISSN : 1961-960X

Éditeur :

CNRS (UMR 7528 Mondes iraniens et indiens), Éditions de l'IFRI

Édition imprimée

Date de publication : 15 mai 2001

ISSN : 0240-8910

\section{Référence électronique}

Christophe Balaÿ, « «Bāz-ḩvānī-e dāstān-e Dāš Ākol ». Kārnāme, n 7, (1378), pp. 63-77. [Relecture du récit de Dāš Ākol] », Abstracta Iranica [En ligne], Volume 22 | 2001, document 544, mis en ligne le 17 février 2010, consulté le 09 octobre 2020. URL : http://journals.openedition.org/abstractairanica/ 37129 ; DOI : https://doi.org/10.4000/abstractairanica.37129

Ce document a été généré automatiquement le 9 octobre 2020.

Tous droits réservés 


\title{
« Bāz-Hูānī-e dāstān-e Dā̌š Ākol ». Kārnāme, no 7, (1378), pp. 63-77. [Relecture du récit de $D \bar{a} \check{s} \bar{A} k o l]$
}

\author{
Christophe Balaÿ
}

1 L'A. revisite la critique de la célèbre nouvelle de Ș. Hedāyat, l'histoire du Lūṭi des bas quartiers qui tombe amoureux de Marjān, sa jeune filleule et meurt de cet amour impossible. L'A. part du principe que la critique littéraire est trop soumise aux seuls critères masculins et propose ici une vision et une interprétation délibérément féministes. Elle revient sur plusieurs aspects de la culture iranienne traditionnellement masculine (lūtịigarī, javānmardì et le statut de la femme). Le rôle de Marjān, comme elle le montre bien, en apparence second par rapport à celui de Kākā Rostam, est un pivot essentiel pour comprendre l'évolution du caractère de l'homme 嚂 subtile dialectique hégélienne du dominant-dominé. Un par un, l'A. reprend les arguments qui soustendent un discours masculin dominant 医 mais en démontant le système "chevaleresque » et machiste, elle fait apparaître indirectement l'ambiguïté de la pensée de S. Hedāyat, qui ne cesse, dans ses œuvres, de susciter et de révéler les contradictions du système socio-culturel iranien. Finalement, conclut l'A., ce n'est pas tant l'amour impossible qu'il éprouve pour Marjān qui tue Kākā Rostam, mais bien plutôt un ensemble de coutumes, de traditions et de croyances qui l'emprisonnent. Dans cette subtile étude, Hedāyat est une fois encore montré comme un analyste des structures sociales 医 un M. Proust en éclats. 
INDEX

Thèmes : 11.1.2. Littérature persane moderne

\section{AUTEURS}

CHRISTOPHE BALAY

IFRI - Téhéran 